Article

\title{
Twelve-Month Studies on Perilla Oil Intake in Japanese Adults-Possible Supplement for Mental Health
}

\author{
Michio Hashimoto ${ }^{1, *(D)}$, Kentaro Matsuzaki ${ }^{1}$ (D), Setsushi Kato ${ }^{2}$, Shahdat Hossain ${ }^{1,3}$, \\ Miho Ohno ${ }^{2}$ and Osamu Shido ${ }^{1}$
}

1 Department of Environmental Physiology, Shimane University Faculty of Medicine, Izumo 693-8501, Japan; matuzaki@med.shimane-u.ac.jp (K.M.); shahdat@juniv.edu (S.H.); o-shido@med.shimane-u.ac.jp (O.S.)

2 Kato Hospital, Jinjukai Healthcare Corporation, Kawamoto, Shimane 696-0001, Japan; katosetsu@k-jinju.or.jp (S.K.); ohno@k-jinju.or.jp (M.O.)

3 Department of Biochemistry and Molecular Biology, Jahangirnagar University, Savar, Dhaka 1342, Bangladesh

* Correspondence: michio1@med.shimane-u.ac.jp; Tel.: +81-853-20-2730

Received: 19 March 2020; Accepted: 21 April 2020; Published: 22 April 2020

\begin{abstract}
Perilla oil (PO), rich in $\alpha$-linolenic acid (LNA, C18:3, $\omega-3)$, is increasingly alleged to have numerous health benefits in humans. However, the current reports detailing the effects of PO on human mental health are not adequate. Therefore, in the current investigation we compared the effects of PO or placebo treatment on the mental condition of healthy adult Japanese volunteers. At baseline and after 12 months of treatment, mental health condition was assessed using the Zung Self-Rating Depression Scale (SDS) and Apathy Scale, and serum biochemical parameters were determined. From baseline to 12 months of intervention, both SDS depression and apathy scores improved significantly in the PO-administered group. Compared to those of control group, serum norepinephrine and serotonin levels after 12 months decreased in the PO-administered group. The enhanced mental state observed in PO-subjects was accompanied by LNA level increases in erythrocyte plasma membranes. Our data demonstrate that PO intake enhances blood LNA levels and may maintain healthy mental conditions in adult subjects.
\end{abstract}

Keywords: perilla oil; $\alpha$-linolenic acid; mental health; depression; apathy; $\omega$-polyunsaturated fatty acid

\section{Introduction}

Numerous reports suggest that $\omega-3$ polyunsaturated fatty acids (PUFAs) have major roles in the maintenance and sustenance of brain cognition in both animals and humans [1-3]. Fats and oils, such as docosahexaenoic acid (DHA), can enrich the brain with essential fatty acids, and dietary lipids therefore appear to be an important factor for brain fatty acid nutrition. Many studies support the notion that dietary lipid selection significantly correlates with human ailments such as obesity, atherosclerosis, hypertension, stroke, diabetes, and brain cognition [4]. Furthermore, high fat diet increases brain neuroinflammation [5], which can also affect cognition. The increase in $\omega-6 / \omega-3$ PUFA ratios found in western diets is associated with the increased incidence of depression [6]. Tsuboi et al. (2013) [7] reported that increased levels of serum saturated fatty acids and $\omega-6$ PUFAs such as arachidonic acid (AA, C22:4, $\omega-6)$, are associated with depression. On the contrary, $\omega-3$ PUFAs are involved in the attenuation of neuro-inflammation [8], prevention of neuronal death [9], and development of cognitive ability $[10,11]$ and improvement of mood disorders in humans and animals [12-14]. These reports 
support the concept that brain inflammation, depression, and anxiety seen in patients suffering from mental disorders may be related to a deficiency in $\omega-3$ PUFAs.

Perilla oil (PO) is considered a rich source of $\omega-3$ PUFAs, as it is comprised chiefly of $\alpha$-linolenic (LNA; $18: 3, \omega-3 ; 54-64 \%$ ) and linoleic (13-20\%) acid. PO also contains $12-22 \%$ monounsaturated oleic acid (OLA), and a small percentage of saturated fatty acids such as palmitic (PLA; 5-7\%) and stearic (STA; $1-3 \%$ ) acid. Notably, amongst the plant seed-based oils, PO possesses the highest proportion of $\omega-3$ fatty acids, the most notable of which is LNA [15]. Other than acting as an anti-thrombotic [16], antiarrhythmic [17] and anti-inflammatory $[18,19]$ fatty acid, LNA is believed to have neuroprotective effects [20]. LNA intake has previously been associated with reduced incidence of myocardial infarction [21], atherosclerosis [22], and mortality from coronary artery disease [23]. Because of the positive impact of LNA's metabolites, such as eicosapentaenoic acid (EPA) and DHA, on learning-related memory in young and old rats [10,24] as well as Alzheimer's disease (AD) in model rats [25,26], linoleic acid (LLA), being the precursor of EPA and DHA, is also gaining increasing interest for improving brain cognition. Direct application of purified LNA to glial cell lines inhibited Amyloid $\beta$-induced oxidative stress [27]. Neuronal cell lines pretreated with LNA also inhibited $\mathrm{H}_{2} \mathrm{O}_{2}$-induced apoptotic neuronal cell death [28], thus suggesting that LNA has significant antioxidative potential. However, the reports detailing the effects of $\mathrm{PO}$ on human cognitive function and mental health are not adequate. In the current study, we investigated the effects of LNA-rich PO on mental condition in Japanese adults.

\section{Materials and Methods}

\subsection{Participants}

A 12-month randomized, double-blind, placebo-controlled study was conducted among healthy 30-78 years old adults living in Okazaki, Japan. All participants underwent anthropometric, blood biochemistry, and mental health tests. Participants were excluded if they had evidence of a medical disorder including renal, respiratory, cardiac, or hepatic disease, diabetes mellitus, and endocrine, metabolic, or hematological disturbances, or were using any psychotropic drug/supplement that might significantly influence the outcomes of the study, or had a hypersensitivity or allergy to PO.

Participants were divided into two groups: a placebo group $(\mathrm{n}=37)$ who consumed $7.0 \mathrm{~mL}$ (contained in an aluminum package) of olive oil daily, and a PO group $(\mathrm{n}=38)$ who consumed $7.0 \mathrm{~mL}$ (contained in the identical aluminum package) of PO daily (The composition of PO is shown in Table 1). Neither participants nor researchers knew what capsules were being taken by each individual. Both PO and placebo capsules were identically packaged, and had no difference in appearance, texture, or smell. Both oils were provided by Ota Oil Co. Ltd., (Okazaki, Japan). This study was conducted according to the principles of the Declaration of Helsinki and Good Clinical Practice, and was approved by the Ethics Committee of Kato Hospital (approval number 2015-0017). All participants provided written informed consent before participation. Hospital nurses measured participant body weight, height, and blood pressure. Participants were then asked to answer a self-reported general questionnaire on lifestyle, including questions related to medical history, and a brief diet history questionnaire.

Table 1. Basic fatty acid composition of placebo and perilla oil.

\begin{tabular}{ccc}
\hline Fatty Acids $(\mathrm{g} / \mathbf{1 0 0} \mathbf{~ m L})$ & Placebo & Perilla Oil \\
\hline PLA (C16:0) & $9.45 \pm 0.05$ & $6.55 \pm 0.05$ \\
PAL (C16:1, $\omega-9)$ & $0.20 \pm 0.0$ & $0.20 \pm 0.00$ \\
STA (C18:0) & $2.95 \pm 0.07$ & $1.60 \pm 0.10$ \\
OLA (C16:0, $\omega-9)$ & $39.6 \pm 0.07$ & $27.15 \pm 0.25$ \\
LLA (C18:2, $\omega-6)$ & $42.0 \pm 0.05$ & $14.0 \pm 0.75$ \\
LNA (C18:3, $\omega-3)$ & $5.45 \pm 0.05$ & $50.4 \pm 0.55$
\end{tabular}

PLA: palmitic acid; PAL: palmitoleic acid; STA: stearic acid; OLA: oleic acid; LLA: linoleic acid; LNA: $\alpha$-linolenic acid. Data are mean $\pm \mathrm{SE}$, for triplicate determinations. 


\subsection{Blood Sampling and Cognitive Evaluations of Mental Health}

At baseline, and after 12 months of intervention, blood samples were obtained in the morning or afternoon, after ascertaining that the participants had eaten breakfast or lunch. Serum separated from whole blood samples was stored at $-80^{\circ} \mathrm{C}$ within $8 \mathrm{~h}$ of collection. Additionally, blood was collected following 3 and 6 months of intervention in order to monitor LNA, EPA, and DHA levels in the erythrocyte plasma membranes. Mental health condition was assessed at baseline, 3 months and 12 months using the Japanese version of Starktein's Apathy Scale and the Zung Self-Rating Depression Scale (SDS) $[29,30]$.

\subsection{Blood Biochemical Analysis}

Serum biochemical variables, glutamate-pyruvate transaminase (GPT), glutamate-oxaloacetate transaminase (GOT), gamma-glutamyl transpeptidase ( $\gamma$-GT), high-density lipoprotein cholesterol (HDL-C), low-density lipoprotein cholesterol (LDL-C), triglyceride (TG), total cholesterol (TC), albumin (ALB), blood urea nitrogen (BUN), and creatinine (CRE) were measured with an automated analyzer 7700DDPP (Hitachi, Tokyo, Japan). Serum glycated hemoglobin (HbA1c) levels were determined using high-performance liquid chromatography (HPLC; HLC-723G9; TOSOH, Tokyo, Japan), and blood sugar (BS) was measured with an automatic analyzer GA08II (A\&T Co., Kanagawa, Japan). Fatty acid composition was determined using gas chromatography, as previously described [31].

Monoamine concentrations, norepinephrine (NE), epinephrine (Epi), dopamine (DA), and 5-hydroxytryptamine (5-HT (serotonin)) in the serum were measured using a previously described HPLC method [32]. Briefly, serum was pretreated with clean column EG (EICOM, Kyoto, Japan). The HPLC equipment consisted of an EICOM HTEC-500 (EICOM), equipped with a data processor (EICOM EPC-500 PowerChrom) and an automatic injector (EICOM M-514). Chromatographic separation was performed using an EICOMPAK CA-5ODS column $(2.1 \mathrm{~mm} \times 150 \mathrm{~mm}$ ID) linked to a precolumn (EICOM PREPAK PC-03-CA, $3.0 \mathrm{~mm}$ ID). PowerChrom software was used for data collection and analysis (EICOM). The mobile phase consisted of $0.1 \mathrm{M}$ phosphate buffer ( $\mathrm{pH}$ 5.7) containing $12 \%$ methanol, $700 \mathrm{mg} / \mathrm{L}$ sodium 1-octanesulfonate, and $50 \mathrm{mg} / \mathrm{L}$ EDTA disodium salt. The flow rate was $0.23 \mathrm{~mL} / \mathrm{min}$, and the applied potential was $+450 \mathrm{mV}$ over an $\mathrm{Ag} / \mathrm{AgCl}$ reference electrode. Column temperature was maintained at $25^{\circ} \mathrm{C}$.

\subsection{Statistical Analysis}

Basic fatty acid composition of placebo and perilla oil (Table 1 ) changes $(\Delta)$ in the SDS scores or Apathy scores, from baseline to 3 months or 12 months, in the PO-intake group and placebo groups (Figure 1); and fatty acid profile of the erythrocyte plasma membranes at baseline and 12 months (Table 4) were expressed as mean \pm SE. Student's $t$-test was used to evaluate differences in demographic and baseline variables. Participant's parameters at base line (Table 2) and at 12 months (Table 3) were expressed as mean value, median value with the minimum (Min) and maximum (Max) levels. These values were analyzed by Mann-Whitney U test. Changes in LNA, EPA and DHA levels of erythrocyte plasma membrane every three months were analyzed by Two-way analysis of variance (ANOVA) followed by Bonferroni's post hoc test (Figure 2). All analyses were carried out using PASW Statistics software (Version 18.0; SPSS Inc.; Chicago, IL, USA). All hypothetical tests were two-sided, and significance was reported as $p<0.05$. 
A

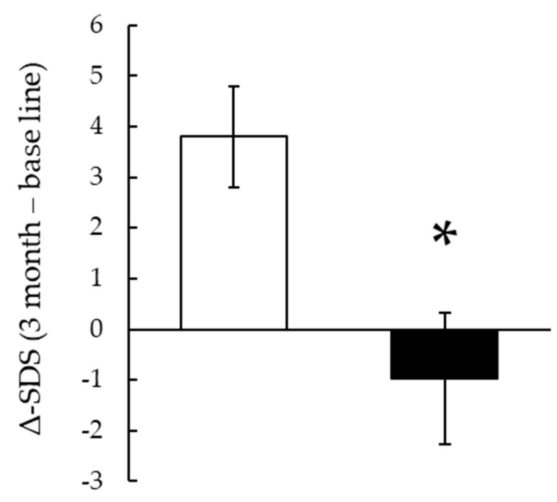

Placebo Perilla oil

C

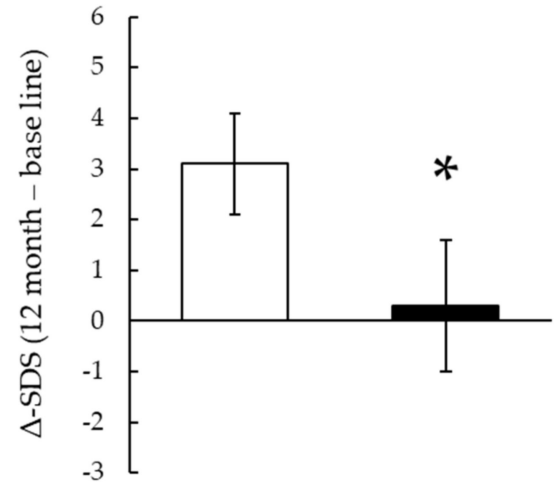

Placebo Perilla oil
B
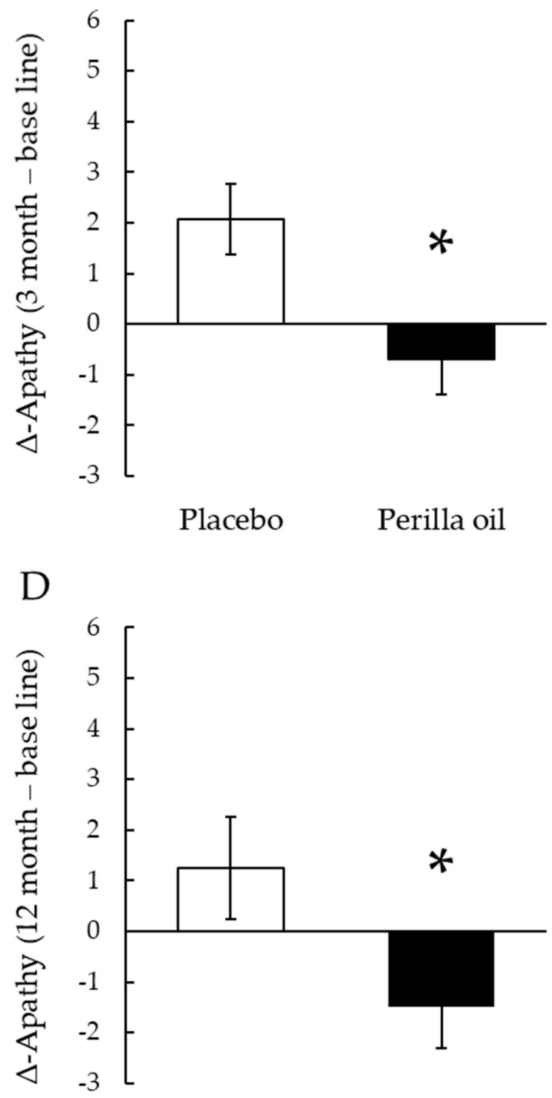

Placebo Perilla oil

Figure 1. Effect on PO-administration on SDS and Apathy scores. Changes $(\Delta)$ in the SDS scores or Apathy scores from baseline to 3 months $(\mathbf{A}, \mathbf{B})$ or 12 months $(\mathbf{C}, \mathbf{D})$ in the PO-intake group and placebo groups. Results are means \pm SE. ${ }^{*} p<0.05$.

A

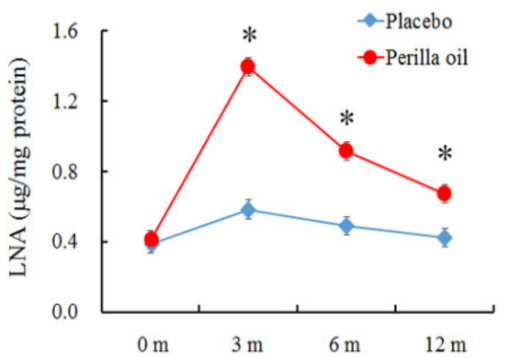

B

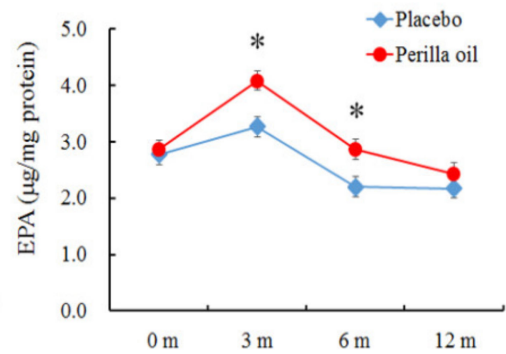

C

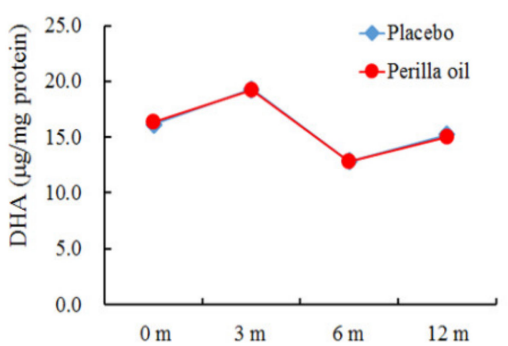

Figure 2. Effect on PO-administration on erythrocyte plasma membrane (A) LNA, $\alpha$-linolenic acid; (B) EPA, eicosapentaenoic acid; and (C) DHA, docosahexaenoic acid. m: Months. Placebo, $\mathrm{n}=34$. Perilla oil, $\mathrm{n}=31$. Results are means $\pm \mathrm{SE}$. ${ }^{*} p<0.05$. 
Table 2. Participant's base line parameters.

\begin{tabular}{|c|c|c|c|c|c|c|c|c|c|}
\hline & \multicolumn{4}{|c|}{ Placebo $(n=37)$} & \multicolumn{4}{|c|}{ Perilla Oil $(\mathrm{n}=38)$} & \multirow[b]{2}{*}{$p$ Value } \\
\hline & Mean & Median & Min & $\operatorname{Max}$ & Mean & Median & Min & Max & \\
\hline Sex (male/female) & $16 / 21$ & & & & $16 / 22$ & & & & \\
\hline Age (years) & 47.8 & 48.0 & 30 & 65 & 48.9 & 49.0 & 31 & 78 & 0.963 \\
\hline Height (cm) & 161.3 & 162.5 & 146.6 & 175.5 & 161.0 & 159.6 & 137.0 & 174.3 & 0.727 \\
\hline Body Weight (kg) & 61.7 & 63.3 & 42.3 & 91.2 & 61.3 & 59.3 & 40.2 & 96.0 & 0.875 \\
\hline BMI $\left(\mathrm{kg} / \mathrm{m}^{2}\right)$ & 23.6 & 23.1 & 16.1 & 33.4 & 23.5 & 23.1 & 16.2 & 33.4 & 0.940 \\
\hline $\mathrm{BC}(\mathrm{cm})$ & 82.1 & 83.5 & 63.0 & 104.0 & 83.7 & 83.3 & 60.0 & 108.0 & 0.526 \\
\hline Body fat (\%) & 28.4 & 26.9 & 11.0 & 48.2 & 29.8 & 30.7 & 11.4 & 46.4 & 0.347 \\
\hline SW (kg) & 57.3 & 57.9 & 47.3 & 67.8 & 57.2 & 56.1 & 41.3 & 66.8 & 0.754 \\
\hline \multicolumn{10}{|l|}{ Blood Pressure } \\
\hline SBP (mmHg) & 123.8 & 127.0 & 90.0 & 159.0 & 124.2 & 125.0 & 98.0 & 160.0 & 0.790 \\
\hline DBP (mmHg) & 76.2 & 78.0 & 55.0 & 98.0 & 76.1 & 77.5 & 58.0 & 94.0 & 0.583 \\
\hline \multicolumn{10}{|l|}{ Emotional index } \\
\hline SDS score & 35.1 & 34.0 & 23.0 & 56.0 & 36.4 & 36.5 & 22.0 & 54.0 & 0.373 \\
\hline Apathy score & 12.4 & 12.0 & 0.0 & 25.0 & 14.6 & 15.0 & 3.0 & 26.0 & 0.205 \\
\hline \multicolumn{10}{|l|}{ Blood biochemistry } \\
\hline GOT (U/L) & 21.8 & 21.0 & 14.0 & 69.0 & 22.0 & 19.0 & 15.0 & 48.0 & 0.821 \\
\hline GPT (U/L) & 21.9 & 19.5 & 10.0 & 101.0 & 22.3 & 16.0 & 9.0 & 83.0 & 0.820 \\
\hline$\gamma$-GT (IU/L) & 33.0 & 25.0 & 11.0 & 331.0 & 39.7 & 25.0 & 13.0 & 189.0 & 0.808 \\
\hline $\operatorname{ALB}(\mathrm{g} / \mathrm{dL})$ & 4.6 & 4.6 & 4.0 & 5.3 & 4.6 & 4.5 & 4.2 & 5.3 & 0.995 \\
\hline $\mathrm{TC}(\mathrm{mg} / \mathrm{dL})$ & 210.7 & 210.5 & 90.0 & 397.0 & 217.9 & 216.0 & 163.0 & 285.0 & 0.700 \\
\hline $\mathrm{TG}(\mathrm{mg} / \mathrm{dL})$ & 96.4 & 85.0 & 35.0 & 277.0 & 101.1 & 88.0 & 38 & 268.0 & 0.312 \\
\hline BUN (mg/dL) & 12.7 & 12.8 & 6.8 & 19.7 & 12.8 & 12.7 & 7.0 & 24.9 & 0.740 \\
\hline CRE (mg/dL) & 0.8 & 0.7 & 0.5 & 1.1 & 0.7 & 0.7 & 0.6 & 1.3 & 0.905 \\
\hline $\mathrm{BS}(\mathrm{mg} / \mathrm{dL})$ & 94.5 & 94.5 & 76.0 & 145.0 & 95.7 & 92.0 & 79.0 & 161.0 & 0.667 \\
\hline HDL-C (mg/dL) & 65.7 & 64.0 & 27.2 & 108.4 & 68.4 & 63.2 & 44.4 & 112.8 & 0.261 \\
\hline LDL-C (mg/dL) & 130.4 & 127.9 & 19.9 & 213.0 & 134.2 & 130.0 & 84.0 & 194.0 & 0.305 \\
\hline HbA1c (NGSP) (\%) & 5.7 & 5.7 & 5.0 & 9.1 & 5.8 & 5.7 & 5.1 & 8.0 & 0.612 \\
\hline $\mathrm{NE}(\mathrm{pg} / 100 \mu \mathrm{L})$ & 60.9 & 57.0 & 24.6 & 120.0 & 63.2 & 55.2 & 30.8 & 139.0 & 0.713 \\
\hline Epi $(\mathrm{pg} / 100 \mu \mathrm{L})$ & 4.7 & 3.7 & 1.5 & 11.8 & 5.4 & 4.3 & 0.8 & 20.2 & 0.596 \\
\hline $5-\mathrm{HT}(\mathrm{pg} / 100 \mu \mathrm{L})$ & 28,839 & 24,559 & 8355 & 75,752 & 29,652 & 25,242 & 10,524 & 99,019 & 0.949 \\
\hline
\end{tabular}

BC: belly circumference; BMI: body mass index; SW: standard weight; SBP: systolic blood pressure; DBP: diastolic blood pressure; SDS: self-rating depression scale; GOT: glutamate-oxaloacetate transaminase; GPT: glutamate-pyruvate transaminase; $\gamma$-GT: gamma-glutamyl transpeptidase; ALB: albumin; TC: total cholesterol; TG: triglyceride; BUN: blood urea nitrogen; CRE: creatinine; BS: blood sugar; HDL-C: high-density lipoprotein cholesterol; LDL-C: low-density lipoprotein cholesterol; HbA1c: glycated hemoglobin; NE: norepinephrine; Epi: epinephrine; 5-HT: 5-hydroxytryptamine (serotonin). Min: minimum value; Max: maximum value.

Table 3. Participant's parameters after 12 months intervention.

\begin{tabular}{|c|c|c|c|c|c|c|c|c|c|}
\hline & \multicolumn{4}{|c|}{ Placebo $(n=34)$} & \multicolumn{4}{|c|}{ Perilla Oil $(\mathrm{n}=31)$} & \multirow[b]{2}{*}{$p$ Value } \\
\hline & Mean & Median & Min & Max & Mean & Median & Min & Max & \\
\hline Sex (male/female) & $14 / 20$ & & & & $12 / 19$ & & & & \\
\hline Age (years) & 49.0 & 49.2 & 31 & 66 & 50.6 & 50.0 & 32 & 79 & 0.534 \\
\hline Height $(\mathrm{cm})$ & 161.8 & 162.9 & 146.7 & 175.5 & 160.0 & 160.0 & 136.9 & 174.5 & 0.308 \\
\hline Body Weight (kg) & 62.5 & 62.1 & 43.2 & 93.4 & 61.1 & 59.1 & 40.9 & 96.5 & 0.657 \\
\hline $\operatorname{BMI}\left(\mathrm{kg} / \mathrm{m}^{2}\right)$ & 23.8 & 22.9 & 17.1 & 34.1 & 23.8 & 23.8 & 17.3 & 32.8 & 0.993 \\
\hline $\mathrm{BC}(\mathrm{cm})$ & 83.6 & 83.9 & 66.0 & 102.0 & 84.5 & 83.6 & 66.3 & 109.7 & 0.741 \\
\hline Body fat $(\%)$ & 28.4 & 28.5 & 17.1 & 48.1 & 29.3 & 30.7 & 9.5 & 42.9 & 0.659 \\
\hline $\mathrm{SW}(\mathrm{kg})$ & 57.8 & 58.5 & 47.2 & 67.5 & 56.6 & 56.0 & 41.3 & 66.8 & 0.334 \\
\hline \multicolumn{10}{|l|}{ Blood Pressure } \\
\hline SBP (mmHg) & 121.5 & 126.0 & 93.0 & 146.0 & 120.0 & 123.0 & 92.0 & 151.0 & 0.673 \\
\hline $\mathrm{DBP}(\mathrm{mmHg})$ & 74.6 & 75.5 & 54.0 & 90.0 & 73.7 & 76.0 & 54.0 & 88.0 & 0.729 \\
\hline \multicolumn{10}{|l|}{ Emotional index } \\
\hline SDS score & 37.9 & 36.0 & 29.0 & 55.0 & 37.4 & 36.0 & 20.0 & 61.0 & 0.805 \\
\hline Apathy score & 13.9 & 13.5 & 0.0 & 26.0 & 12.8 & 16.0 & 0.0 & 21.0 & 0.496 \\
\hline \multicolumn{10}{|l|}{ Blood biochemistry } \\
\hline GOT (U/L) & 22.3 & 21.0 & 14.0 & 55.0 & 23.5 & 21.0 & 14.0 & 52.0 & 0.529 \\
\hline GPT (U/L) & 20.7 & 17.5 & 10.0 & 62.0 & 20.0 & 16.0 & 7.0 & 66.0 & 0.814 \\
\hline$\gamma-\mathrm{GT}(\mathrm{IU} / \mathrm{L})$ & 32.8 & 23.0 & 8.0 & 250.0 & 40.6 & 23.0 & 13.0 & 314.0 & 0.531 \\
\hline $\operatorname{ALB}(\mathrm{g} / \mathrm{dL})$ & 4.5 & 4.6 & 3.2 & 5.3 & 4.6 & 4.6 & 4.2 & 5.0 & 0.746 \\
\hline
\end{tabular}


Table 3. Cont

\begin{tabular}{cccccccccc}
\hline & \multicolumn{3}{c}{ Placebo $(\mathbf{n}=\mathbf{3 4})$} & \multicolumn{7}{c}{ Perilla Oil (n=31) } \\
\hline & Mean & Median & Min & Max & Mean & Median & Min & Max & $p$ Value \\
\hline TC $(\mathrm{mg} / \mathrm{dL})$ & 204.0 & 201.0 & 143.0 & 282.0 & 209.5 & 206.0 & 163.0 & 305.0 & 0.496 \\
TG $(\mathrm{mg} / \mathrm{dL})$ & 117.8 & 79.5 & 41.0 & 713.0 & 99.4 & 89.0 & 38.0 & 307.0 & 0.435 \\
BUN $(\mathrm{mg} / \mathrm{dL})$ & 12.6 & 13.0 & 5.5 & 17.6 & 13.7 & 13.4 & 8.2 & 26.5 & 0.195 \\
CRE (mg/dL) & 0.7 & 0.7 & 0.4 & 1.1 & 0.7 & 0.7 & 0.5 & 1.4 & 0.821 \\
BS (mg/dL) & 93.3 & 93.5 & 71.0 & 123.0 & 93.6 & 92.0 & 82.0 & 119.0 & 0.900 \\
HDL-C (mg/dL) & 63.5 & 59.2 & 41.6 & 110.9 & 66.4 & 64.5 & 34.7 & 111.2 & 0.515 \\
LDL-C (mg/dL) & 123.2 & 125.5 & 73.0 & 177.0 & 128.8 & 127.0 & 87.0 & 204.0 & 0.387 \\
HbA1c (NGSP) $(\%)$ & 5.6 & 5.5 & 4.2 & 6.6 & 5.7 & 5.7 & 4.9 & 6.6 & 0.436 \\
NE (pg/100 $\mu \mathrm{L})$ & 42.4 & 39.3 & 12.1 & 100.1 & 49.3 & 47.3 & 20.1 & 98.9 & 0.142 \\
Epi $(\mathrm{pg} / 100 \mu \mathrm{L})$ & 4.7 & 4.8 & 1.3 & 9.8 & 5.2 & 4.1 & 1.5 & 18.0 & 0.494 \\
5-HT $(\mathrm{pg} / 100 \mu \mathrm{L})$ & 22,363 & 18,460 & 4697 & 58,833 & 21620 & 20,071 & 4066 & 62,820 & 0.812 \\
\hline
\end{tabular}

BC: belly circumference; BMI: body mass index; SW: standard weight; SBP: systolic blood pressure; DBP: diastolic blood pressure; SDS: self-rating depression scale; GOT: glutamate-oxaloacetate transaminase; GPT: glutamate-pyruvate transaminase; $\gamma$-GT: gamma-glutamyl transpeptidase; ALB: albumin; TC: total cholesterol; TG: triglyceride; BUN: blood urea nitrogen; CRE: creatinine; BS: blood sugar; HDL-C: high-density lipoprotein cholesterol; LDL-C: low-density lipoprotein cholesterol; HbA1c: glycated hemoglobin; NE: norepinephrine; Epi: epinephrine; 5-HT: 5-hydroxytryptamine (serotonin). Min: minimum value; Max: maximum value.

\section{Results}

\subsection{Demographic and Clinical Characteristics at Baseline}

A total of 75 participants (43 women and 32 men) completed all baseline assessments and were randomized to either the placebo or PO group. A total of 65 participants $(86.3 \%)$ completed the study in its entirety. Excluding individuals who withdrew from the study did not leave a significant difference in sample size between groups. All baseline characteristics are shown in Table 2. There were no significant between-group differences in sex, age, body weight, belly circumference, body mass index (BMI), body fat, blood pressure, or serum biochemical parameters.

\subsection{Nutritional Intake}

There was no significant difference in mean 12-month dietary nutritional intake between placebo and PO groups. No noticeable side-effects that disturbed daily life (allergic reactions, palpitations, stomach irritation, etc.) were found in either group.

\subsection{Effect of PO-Administration on Mental Health}

The changes $(\Delta)$ in SDS and apathy scores from baseline to 3 months were significantly lower in the PO group (Figure 1A, $p=0.024$; and B, $p=0.008$ ). Moreover, $\Delta$-SDS and $\Delta$-Apathy scores in PO group at 12 months were significantly lower than those of placebo group (Figure $1 \mathrm{C}, p=0.037$; $1 \mathrm{D}, p=0.031$ ). Additionally, a gender difference in $\Delta$-SDS score from baseline to 12 months in the PO and placebo groups was analyzed. $\triangle$-SDS score in women was significantly lower in the PO group than that of placebo group ( $p=0.041)$, while no significant difference was observed in men $(p=0.459$, Supplementary Materials Figure S1).

\subsection{Effect of PO-Administration on Body Constitution and Serum Biochemical Parameters}

There were no significant differences between groups in height, body weight, BMI, or blood pressure at month 12 (Table 3). Correspondingly, the placebo and PO groups did not differ in their blood biochemistry parameters (Table 3 ).

\subsection{Effect of PO-Administration on the Fatty Acid Profile of Erythrocyte Plasma Membrane}

The erythrocyte plasma membrane fatty acid profile, monitored at baseline and following 12 months of treatment, is shown in Table 4. Other than LNA, which significantly increased over time 
in PO subjects, erythrocyte plasma membrane fatty acid levels did not change. No fatty acid levels changed over time in placebo-administered subjects.

Table 4. Fatty acid profile of the erythrocyte plasma membranes at baseline and 12 months of perilla oil intervention.

\begin{tabular}{ccccc}
\hline & \multicolumn{2}{c}{ Baseline } & \multicolumn{2}{c}{ 12-Months } \\
\cline { 2 - 5 }$(\boldsymbol{\mu g} / \mathbf{m g}$ & Placebo & $\begin{array}{c}\text { Perilla } \text { Oil } \\
\mathbf{n}=\mathbf{3 8}\end{array}$ & $\begin{array}{c}\text { Placebo } \\
\mathbf{n}=\mathbf{3 4}\end{array}$ & $\begin{array}{c}\text { Perilla } \text { Oil } \\
\mathbf{n}=\mathbf{3 1}\end{array}$ \\
\hline Protein) & $47.8 \pm 0.7$ & $49.0 \pm 0.8$ & $33.0 \pm 0.5$ & $32.9 \pm 0.7$ \\
PLA & $41.2 \pm 0.7$ & $41.5 \pm 0.7$ & $27.8 \pm 0.5$ & $28.0 \pm 0.8$ \\
STA & $32.0 \pm 0.5$ & $32.9 \pm 0.6$ & $25.8 \pm 0.6$ & $25.6 \pm 0.5$ \\
OLA & $26.4 \pm 0.5$ & $26.5 \pm 0.7$ & $24.0 \pm 0.6$ & $23.4 \pm 0.6$ \\
LLA & $0.39 \pm 0.02$ & $0.41 \pm 0.03$ & $0.42 \pm 0.03$ & $0.67 \pm 0.05 *$ \\
LNA & $30.3 \pm 0.6$ & $30.8 \pm 0.5$ & $23.9 \pm 0.7$ & $23.2 \pm 0.6$ \\
AA & $2.8 \pm 0.2$ & $2.9 \pm 0.2$ & $2.2 \pm 0.2$ & $2.4 \pm 0.1$ \\
EPA & $4.9 \pm 0.1$ & $4.8 \pm 0.1$ & $3.1 \pm 0.1$ & $3.2 \pm 0.1$ \\
DPA & $7.4 \pm 0.3$ & $7.6 \pm 0.2$ & $9.7 \pm 0.2$ & $9.6 \pm 0.2$ \\
C24:0 & $16.1 \pm 0.4$ & $16.3 \pm 0.4$ & $15.2 \pm 0.6$ & $15.0 \pm 0.5$ \\
DHA & $7.3 \pm 0.2$ & $7.7 \pm 0.2$ & $7.4 \pm 0.2$ & $7.1 \pm 0.2$ \\
C24:1 & $217.1 \pm 3.4$ & $220.9 \pm 3.4$ & $173.4 \pm 3.1$ & $172.0 \pm 3.3$ \\
Total &
\end{tabular}

PLA: palmitic acid; STA: stearic acid; OLA: oleic acid; LLA: linoleic acid; LNA: $\alpha$-linolenic acid; AA: arachidonic acid; EPA: eicosapentaenoic acid; DPA: docosapentaenoic acid; DHA: docosahexaenoic acid; Data are mean \pm SE. ${ }^{*} p<0.05$ vs. placebo.

LNA, EPA and DHA profiles in the erythrocyte plasma membrane measured at baseline and at 3, 6 and 12 months after treatment are shown in Figure 2. Compared to the LNA levels at baseline in the PO group, it significantly increased by $250.0 \%$ at 3 months after treatment and decreased after that, but it significantly increased by $130.0 \%$ at 6 months and by $67.5 \%$ at 12 months (Figure $2 \mathrm{~A}$ ). These levels were significantly higher in the PO group than the placebo group $(F=21.823, p<0.0001)$ at each time point. Similarly, EPA levels significantly increased by $42.7 \%$ at 3 months after treatment compared to the EPA levels at baseline and then decreased. At month 12, EPA levels decreased to placebo-comparable levels (Figure 2B). EPA levels at month 3 and 6 were higher in PO subjects than placebo control subjects $(F=3.382, p<0.05)$. The levels of DHA in the erythrocyte plasma membranes remained similar between groups for the entirety of the study (Figure $2 \mathrm{C}, p>0.05$ ).

\subsection{Effect of PO-Administration on Serum Monoamine Levels}

From baseline to 12 months of oral PO administration, NE levels decreased by $>30 \%$ in the placebo group, and 21\% in the PO group (Figure 3). The mean change in NE levels from baseline to 12 months was $9 \%$ greater in the placebo group. Epi decreased by $\sim 4 \%$ in the PO group only. Levels of 5-HT (serotonin) decreased by $27 \%$ in the PO group, and $22 \%$ in the placebo group (Figure 3). DA levels did not change in either group after intervention. 
A

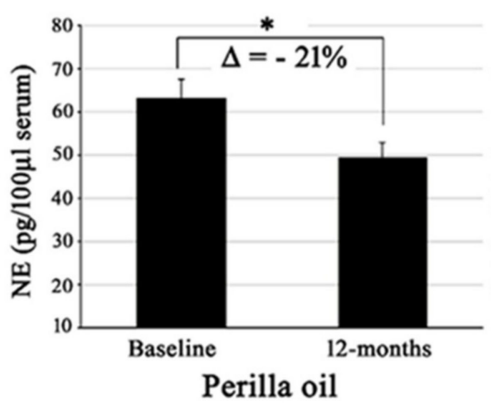

$\mathrm{C}$

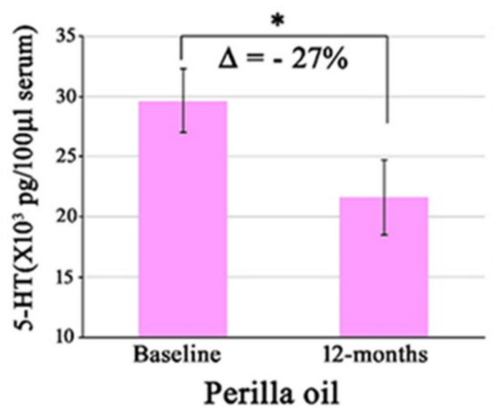

B

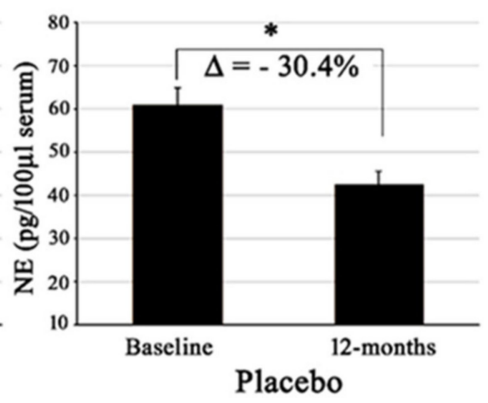

$\mathrm{D}$

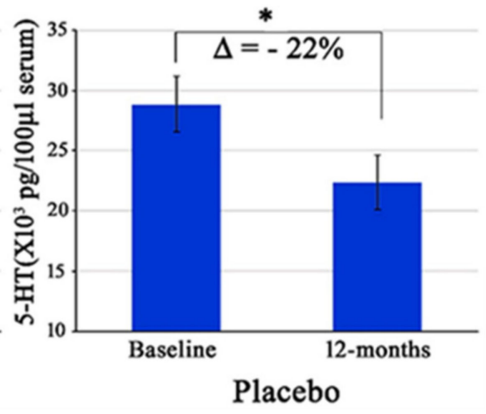

Figure 3. Effect of PO administration on serum norepinephrine (NE) and serotonin (5-HT) levels. There were no inter-group differences, but significant intra-group decreases in serum levels of NE $(\mathbf{A}, \mathbf{B})$ and serotonin $(\mathbf{C}, \mathbf{D})$ were noted in both $\mathrm{PO}$ and placebo groups. $\Delta=$ Changes from baseline to 12 months. Placebo, $\mathrm{n}=34$. Perilla oil, $\mathrm{n}=31,{ }^{*} p<0.05$.

\section{Discussion}

The results of the present study suggest that PO administration enhances blood LNA and EPA levels which may relieve mental conditions such as depression and apathy, as indicated by decreases in Apathy and SDS scores in PO treated subjects compared to their placebo-treated counterparts. Our 12-month interventional study also concludes that $\mathrm{PO}$ administration does not have any negative clinically significant side effects on its users.

The mechanism by which the treatment of PO improved mental condition is not well understood. In general, following digestion and absorption, rises in the levels of dietary components in the erythrocyte membranes reflect their incorporation into cell membranes of other tissues. Consequently, their increased concentrations could be attributed to numerous physiological activities, including brain activity. The levels of LNA in the erythrocyte membranes measured after 3, 6 and 12 months of intervention, as shown in Figure 2, significantly increased. The observed levels of LNA only represent a small percent of total fatty acids in the membranes (Table 4), and its level was highest at month 3. Levels of EPA, an LNA metabolite, were also high following 3 and 6 months of intervention, however, decreased to placebo group-comparable levels after 12 months of treatment. The levels of DHA in the erythrocyte membranes of the PO-intake group did not change during the intervention (Figure 2C). Consistent with our results, consumption of LNA-rich flaxseed oil has previously led to significant increases in tissue EPA, but not DHA [33]. Hamazaki et al. (2006) [34] also reported that PO-intake does not affect the EPA and DHA levels of the human plasma phospholipid fraction. In humans, the antiarrhythmic effect of LNA did not correlate to cell membrane levels of LNA, but correlated rather to its converted metabolites, such as EPA/ DHA, which are usually derived from fish. Dietary LNA does not generally alter DHA levels [35-37]. Therefore, the mechanism(s) of LNA currently benefitting the mental condition of our subjects without significantly increasing tissue DHA levels are unknown. We speculate several possibilities. Our PO dose (4 g/day) may be too low, and a higher 
dose, as used by Finnegan et al. (2003) [38], may have increased tissue LNA levels. Alternatively, enucleated erythrocytes might not be the ideal cell-type to reflect LNA-penetration in other tissue cells. Another thought is that the LNAs contained in the PO may have been exploited for energy sources and/or as substrates for the conversion into lipid mediators through COX/LOX pathways, or via its longer-chained metabolites, such as EPA/DHA. In the present study, serum PO levels in the PO group peaked at month 3 and gradually decreased at month 6 and 12, but the levels at month 12 were significantly higher than that of the control group (Figure 2A). If the amount of PO supplemented is too low and is used as an energy source and/or as substrates of lipid mediators, the intake may need to be increased with a long intake period.

We consider that all these possibilities may coexist. The basis of these speculations are: (i) animals fed LNA-only diets might have brain DHA levels similar to DHA-fed animals [39]; (ii) dietary LNA is sufficiently converted to DHA to increase bioactive lipids derived from DHA in rats [40]; (iii) LNA metabolites can mediate cellular anti-inflammatory effects [41]; (iv) PO-fed rats [40] or cells directly treated with LNA [42] exhibit enhanced $\beta$-oxidation, signifying that LNA is a utilizable energy source; (v) long chain $\omega-3$ PUFAs, including EPA and DHA, are formed from LNA via a series of desaturation and elongation reactions [43]; (vi) vegans and vegetarians, who consume negligible DHA, as it primarily originates from plankton-fed fish and marine animals, depend on LNA to provide adequate DHA to their brains [44-46]; and finally, (vii) the liver maintains the desaturase and elongase enzymes at their highest concentrations as compared to those in the brain $[47,48]$. DHA synthesis in the liver occurs at $>30$-fold higher rates than that in the brain [49]. More interestingly, though the brain is capable of synthesizing DHA $[49,50]$, brain DHA synthesis is 100-fold lower than brain DHA uptake and consumption rates, indicating that brain DHA synthesis does not contribute significantly to brain DHA homeostasis [51]. This suggests an extra-CNS source of DHA for the brain DHA. However, the proportion of LNA used for the purposes mentioned above must be comprehensively evaluated. If the brain has a limited capacity to convert LNA to DHA $(<1 \%)$, other tissues including the liver must have a higher conversion capacity, otherwise, the levels of DHA in a vegan's brain would not increase. Thus, it is conceivable that PO-LNAs may have increased the levels of other lipid mediators, or DHA in the brains of our subjects. However, the mechanism must be known. Unfortunately, we could not directly measure brain levels of EPA or DHA in our current study.

Notably, body weight, BMI, percent body fat, lipid profile (total cholesterol, triglyceride, LDL-cholesterol, HDL-cholesterol), or markers of hepatorenal function (GPT, GOT, $\gamma$-GT, ALB) did not differ between $\mathrm{PO}$ and placebo groups. Systolic blood pressure decreased by $4.2 \mathrm{mmHg}$, while diastolic pressure decreased by $\sim 2.5 \mathrm{mmHg}$ in the $\mathrm{PO}$ group; however, this was not a significant change. These results suggest that long-term PO administration may have no serious side effects in healthy individuals. PO-administration, however, significantly affected serum levels of NE and serotonin. The changes were accompanied by changes in SDS and apathy scores.

SDS score reflect degree of depression, while apathy scores suggest motivational engagement. However, their symptoms usually overlap. The causal relationship between brain lipids, catecholamines, and depression remain unknown. The serotonin theory of depression suggests that reduced levels of serotonin and/or impaired serotonin receptor/transporter function are core pathogenic factors in depression $[52,53]$. Consequently, selective serotonin reuptake inhibitors (SSRIs), which usually increase serotonin levels in the synapse, confer anti-depressant activity. Nevertheless, $50 \%$ of depressive patients do not response to SSRI therapies, and evidence suggests that adequate serotonin levels are only beneficially therapeutic in moderate to severely depressed patients [52,54-56]. Low $\omega-3$ PUFA intake is linked to depression [55], while $\omega-3$ PUFA supplementation enhanced serotonin levels in mice [57] and rats [58]. Previous meta-analytic studies also reported that $\omega-3$ PUFA-intake generally ameliorates depression $[59,60]$. In contrast, DHA-deficient $(25-70 \%$ below normal) brains also had elevated levels of serotonin and its receptors [61], suggesting that the effects of $\omega-3$ PUFAs on serotonin are still inconclusive. In this study, reduced SDS score after 12 months of intervention was associated with reduced serum serotonin levels (Figure 3), but serum serotonin levels were not correlated with 
those of SDS scores (data not shown), suggesting that serum serotonin levels of participants in this study may not be linked to depression.

Additionally, the correlation between $\omega-3$ PUFA and NE levels is yet to be elucidated. Both decreases [62] and lack of change [55,61] in brain NE levels have been observed in the $\omega-3$ PUFA-deficient animal brain. SH-SY5Y neuroblastoma cells pretreated with DHA increased their release of $\left[{ }^{3} \mathrm{H}\right]-\mathrm{NE}$ [63]. Hypothetical mechanisms suggest that $\omega-3$ PUFAs induced increases in neuronal membrane fluidity, release of catecholamines, and enhanced membrane-bound enzyme, receptor, and other signal transducing molecule function $[64,65]$. We have also previously reported that DHA increases the membrane fluidity of synaptosomal plasma membranes [2]. However, the effect of fluidity on catecholamine release and the subsequent action on the human brain and depression seem very complex. In contrast with the effects of $\omega-3$ PUFAs on animal models of depression and/or $\omega-3$ PUFA-deficient animals, there was no prominent increase in serum catecholamine levels in our subjects after 12 months of PO administration. Instead, serum levels of both NE and serotonin significantly decreased in both placebo and PO groups (Figure 3). There are very few studies in this area with which to directly compare our data. We speculate, however, that the changes in catecholamine concentrations brought about an adequate balance between serotonergic and noradrenergic neuronal activity and a neuro-adaptive process. This process ultimately led to a better mental condition in our study subjects, otherwise SDS and apathy scores could not have improved in our PO-intake subjects. Furthermore, PO might have improved the dysregulation of the hypothalamic-pituitary-adrenal axis, which otherwise could have deteriorated the depression and anxiety status of our subjects. Reductions in $\omega-3$ PUFAs, particularly DHA, in the brain have been shown to increase levels of anxiety in mice [66] and rats [67], while dietary $\omega$-3 PUFAs supplementation ameliorated anxiety in rats [68]. Moreover, by decreasing neuroinflammation [9,28,69-71], which is often attributed to depression in humans [72], $\omega-3$ PUFAs may have contributed to maintaining healthy mental condition in our subjects.

We need to mention herein the facts that there are some limitations which deserve additional discussion. Firstly, since the participants in this study were healthy individuals without mental disturbance, their mental health parameters were mostly normal and there were no significant differences between PO group and placebo group. $\Delta$-SDS and $\Delta$-Apathy scores were defined as the difference between the baseline and 3 or 12 months in order to achieve statistical differences, since there were no significant differences in both SDS and Apathy scores between the placebo and PO groups. In the future, we should investigate the effects of $\mathrm{PO}$ ingestion on individuals with mental disorders such as depression. Secondly, we did not control for menstrual cycle or consider menopause for female subjects, and future research will need to take these into account given the influence of menstrual cycle or menopause on psychological health [73-75].

\section{Conclusions}

In conclusion, the current study suggests that PO administration increases blood LNA and EPA levels in the adult subjects, leading to mitigation of mental health issues in adults without having any noticeable clinical side effects. These effects may be a result of the adequate balance between serotonergic and adrenergic neuronal activity. Further investigation is necessary to comprehensively conclude the mechanism responsible for the beneficial effects of PO on mental condition. 
Supplementary Materials: The following are available online at http://www.mdpi.com/2304-8158/9/4/530/s1: Figure S1: The differences between male and female in $\Delta$-SDS score from baseline to 12 months in the PO and placebo groups.

Author Contributions: Conceptualization, M.H.; methodology, M.H., K.M., S.H. and M.O.; software, M.H. and S.H.; validation, M.H., K.M., S.K., S.H., and M.O.; investigation, M.H. and S.H.; formal analysis, M.H. and S.H.; resources, M.H. and S.K.; data curation, M.H., K.M., S.H. and M.O.; writing-original draft preparation, M.H. and S.H.; writing - review and editing, M.H., K.M. and H.S.; visualization, M.H., K.M. and S.H.; supervision, M.H., S.K. and O.S.; project administration, M.H.; funding acquisition, M.H. All authors have read and agreed to the published version of the manuscript.

Funding: This study was supported by a Ministry of Education, Culture, Sports, Science, and Technology of Japan Grant-in-Aid for Scientific Research (C) 23500955 (M.H.).

Acknowledgments: We sincerely thank the participants of the study.

Conflicts of Interest: The authors declare that they have no competing interests.

\section{References}

1. Cardoso, C.; Afonso, C.; Bandarra, N.M. Dietary DHA and health: Cognitive function ageing. Nutr. Res. Rev. 2016, 29, 281-294. [CrossRef] [PubMed]

2. Hashimoto, M.; Hossain, S.; Al Mamun, A.; Matsuzaki, K.; Arai, H. Docosahexaenoic acid: One molecule diverse functions. Crit. Rev. Biotechnol. 2017, 37, 579-597. [CrossRef] [PubMed]

3. Canhada, S.; Castro, K.; Perry, I.S.; Luft, V.C. Omega-3 fatty acids' supplementation in Alzheimer's disease: A systematic review. Nutr. Neurosci. 2018, 21, 529-538. [CrossRef] [PubMed]

4. Haslam, D.W.; James, W.P.T. Obesity. Lancet 2005, 366, 1197-1209. [CrossRef]

5. Pistell, P.J.; Morrison, C.D.; Gupta, S.; Knight, A.G.; Keller, J.N.; Ingram, D.K.; Bruce-Keller, A.J. Cognitive impairment following high fat diet consumption is associated with brain inflammation. J. Neuroimmunol. 2010, 219, 25-32. [CrossRef] [PubMed]

6. Fernandes, M.F.; Mutch, D.M.; Leri, F. The Relationship between Fatty Acids and Different Depression-Related Brain Regions, and Their Potential Role as Biomarkers of Response to Antidepressants. Nutrients 2017, 9, 298. [CrossRef]

7. Tsuboi, H.; Watanabe, M.; Kobayashi, F.; Kimura, K.; Kinae, N. Associations of depressive symptoms with serum proportions of palmitic and arachidonic acids, and alpha-tocopherol effects among male population-A preliminary study. Clin. Nutr. 2013, 32, 289-293. [CrossRef]

8. Tang, M.; Dang, R.; Liu, S.; Zhang, M.; Zheng, Y.; Yang, R.; Yin, T. Omega-3 fatty acids-supplementary in gestation alleviates neuroinflammation and modulates neurochemistry in rats. Lipids Health Dis. 2018, 17, 247. [CrossRef]

9. Luo, C.; Ren, H.; Yao, X.; Shi, Z.; Liang, F.; Kang, J.X.; Wan, J.B.; Pei, Z.; Su, K.P.; Su, H. Enriched Brain Omega-3 Polyunsaturated Fatty Acids Confer Neuroprotection against Microinfarction. EBioMedicine 2018, 32, 50-61. [CrossRef]

10. Gamoh, S.; Hashimoto, M.; Sugioka, K.; Shahdat Hossain, M.; Hata, N.; Misawa, Y.; Masumura, S. Chronic administration of docosahexaenoic acid improves reference memory-related learning ability in young rats. Neuroscience 1999, 93, 237-241. [CrossRef]

11. Hussain, G.; Schmitt, F.; Loeffler, J.P.; Gonzalez de Aguilar, J.L. Fatting the brain: A brief of recent research. Front. Cell. Neurosci. 2013, 7, 144. [CrossRef] [PubMed]

12. Deacon, G.; Kettle, C.; Hayes, D.; Dennis, C.; Tucci, J. Omega 3 polyunsaturated fatty acids and the treatment of depression. Crit. Rev. Food. Sci. Nutr. 2017, 57, 212-223. [CrossRef] [PubMed]

13. Hashimoto, M.; Maekawa, M.; Katakura, M.; Hamasaki, K.; Matsuoka, Y. Possibility of polyunsaturated fatty acids for the prevention and treatment of neuropsychiatric illnesses. J. Pharmacol. Sci. 2014, 124, 294-300. [CrossRef] [PubMed]

14. Sechi, S.; Di Cerbo, A.; Canello, S.; Guidetti, G.; Chiavolelli, F.; Fiore, F.; Cocco, R. Effects in dogs with behavioral disorders of a commercial nutraceutical diet on stress and neuroendocrine parameters. Vet. Rec. 2017, 180, 18-24. [CrossRef]

15. Rao, S.; Abdel-Reheem, M.; Bhella, R.; McCracken, C.; Hildebrand, D. Characteristics of high alpha-linolenic acid accumulation in seed oils. Lipids 2008, 43, 749-755. [CrossRef] 
16. Campos, H.; Baylin, A.; Willett, W.C. $\alpha$-Linolenic acid and risk of nonfatal acute myocardial infarction: Campos: $\alpha$-Linolenic acid myocardial infarction. Circulation 2008, 118, 339-345. [CrossRef]

17. Albert, C.M.; Oh, K.; Whang, W.; Manson, J.E.; Chae, C.U.; Stampfer, M.J.; Willett, W.C.; Hu, F.B. Dietary $\alpha$-linolenic acid intake and risk of sudden cardiac death and coronary heart disease. Circulation 2005, 112, 3232-3238. [CrossRef]

18. Zhao, G.; Etherton, T.D.; Martin, K.R.; Gillies, P.J.; West, S.G.; Kris-Etherton, P.M. Dietary alpha-linolenic acid inhibits proinflammatory cytokine production by peripheral blood mononuclear cells in hypercholesterolemic subjects. Am. J. Clin. Nutr. 2007, 85, 385-391. [CrossRef]

19. Stark, A.H.; Crawford, M.A.; Reifen, R. Update on alpha-linolenic acid. Nutr. Rev. 2008, 66, 326-332. [CrossRef]

20. Nguemeni, C.; Delplanque, B.; Rovere, C.; Simon-Rousseau, N.; Gandin, C.; Agnani, G.; Nahon, J.L.; Heurteaux, C.; Blondeau, N. Dietary supplementation of alpha-linolenic acid in an enriched rapeseed oil diet protects from stroke. Pharmacol. Res. 2010, 61, 226-233. [CrossRef]

21. Baylin, A.; Kabagambe, E.K.; Ascherio, A.; Spiegelman, D.; Campos, H. Adipose tissue $\alpha$-linolenic acid and nonfatal acute myocardial infarction in Costa Rica. Circulation 2003, 107, 1586-1591. [CrossRef] [PubMed]

22. Djousse, L.; Folsom, A.R.; Province, M.A.; Hunt, S.C.; Ellison, R.C. Dietary linolenic acid and carotid atherosclerosis: The National Heart, Lung, and Blood Institute Family Heart Study. Am. J. Clin. Nutr. 2003, 77, 819-825. [CrossRef] [PubMed]

23. Djousse, L.; Pankow, J.S.; Eckfeldt, J.H.; Folsom, A.R.; Hopkins, P.N.; Province, M.A.; Hong, Y.; Ellison, R.C. Relation between dietary linolenic acid and coronary artery disease in the National Heart, Lung, and Blood Institute Family Heart Study. Am. J. Clin. Nutr. 2001, 74, 612-619. [CrossRef] [PubMed]

24. Gamoh, S.; Hashimoto, M.; Hossain, S.; Masumura, S. Chronic administration of docosahexaenoic acid improves the performance of radial arm maze task in aged rats. Clin. Exp. Pharmacol. Physiol. 2001, 28, 266-270. [CrossRef] [PubMed]

25. Hashimoto, M.; Hossain, S.; Shimada, T.; Sugioka, K.; Yamasaki, H.; Fujii, Y.; Ishibashi, Y.; Oka, J.I.; Shido, O. Docosahexaenoic acid provides protection from impairment of learning ability in Alzheimer's disease model rats. J. Neurochem. 2002, 81, 1084-1091. [CrossRef]

26. Hashimoto, M.; Tanabe, Y.; Fujii, Y.; Kikuta, T.; Shibata, H.; Shido, O. Chronic administration of docosahexaenoic acid ameliorates the impairment of spatial cognition learning ability in amyloid beta-infused rats. J. Nutr. 2005, 135, 549-555. [CrossRef]

27. Lee, A.Y.; Choi, J.M.; Lee, M.H.; Lee, J.; Lee, S.; Cho, E.J. Protective effects of perilla oil and alpha linolenic acid on SH-SY5Y neuronal cell death induced by hydrogen peroxide. Nutr. Res. Pract. 2018, 12, 93-100. [CrossRef] [PubMed]

28. Lee, A.Y.; Lee, M.H.; Lee, S.; Cho, E.J. Neuroprotective Effect of Alpha-Linolenic Acid against Abeta-Mediated Inflammatory Responses in C6 Glial Cell. J. Agric. Food. Chem. 2018, 66, 4853-4861. [CrossRef]

29. Okada, K.; Kobayashi, S.; Aoki, K.; Suyama, N.; Yamaguchi, S. Assessment of motivational loss in poststroke patients using the Japanese version of Starkstein's Apathy Scale. Jpn. J. Stroke 1998, 20, 318-327. [CrossRef]

30. Zung, W.W. A self-rating depression scale. Arch. Gen. Psychiatry 1965, 12, 63-70. [CrossRef]

31. Hashimoto, M.; Shinozuka, K.; Gamoh, S.; Tanabe, Y.; Hossain, M.S.; Kwon, Y.M.; Hata, N.; Misawa, Y.; Kunitomo, M.; Masumura, S. The hypotensive effect of docosahexaenoic acid is associated with the enhanced release of ATP from the caudal artery of aged rats. J. Nutr. 1999, 129, 70-76. [CrossRef] [PubMed]

32. Yamasaki, I.; Takagi, T.; Oikawa, D.; Koutoku, T.; Koga, Y.; Tomonaga, S.; Tachibana, T.; Denbow, M.D.; Furuse, M. Changes in catecholamines and dopaminergic metabolites in pigeon brain during development from the late embryonic stage toward hatch. Zoolog. Sci. 2003, 20, 551-555. [CrossRef]

33. Mantzioris, E.; James, M.J.; Gibson, R.A.; Cleland, L.G. Dietary substitution with an alpha-linolenic acid-rich vegetable oil increases eicosapentaenoic acid concentrations in tissues. Am. J. Clin. Nutr. 1994, 59, 1304-1309. [CrossRef] [PubMed]

34. Hamazaki, K.; Itomura, M.; Hamazaki, T.; Sawazaki, S. Effects of cooking plant oils on recurrent aphthous stomatitis: A randomized, placebo-controlled, double-blind trial. Nutrition 2006, 22, 534-538. [CrossRef]

35. Mantzioris, E.; James, M.J.; Gibson, R.A.; Cleland, L.G. Differences exist in the relationships between dietary linoleic and alpha-linolenic acids and their respective long-chain metabolites. Am. J. Clin. Nutr. 1995, 61, 320-324. [CrossRef] 
36. Francois, C.A.; Connor, S.L.; Bolewicz, L.C.; Connor, W.E. Supplementing lactating women with flaxseed oil does not increase docosahexaenoic acid in their milk. Am. J. Clin. Nutr. 2003, 77, 226-233. [CrossRef] [PubMed]

37. Leng, S.; Aukema, H.M. Dietary $\alpha$-Linolenic Acid (ALA) is Sufficiently Converted to Docosahexaenoic Acid (DHA) to Increase Bioactive Lipids Derived from DHA. FASEB J. 2016, 30. [CrossRef]

38. Finnegan, Y.E.; Minihane, A.M.; Leigh-Firbank, E.C.; Kew, S.; Meijer, G.W.; Muggli, R.; Calder, P.C.; Williams, C.M. Plant- and marine-derived n-3 polyunsaturated fatty acids have differential effects on fasting and postprandial blood lipid concentrations and on the susceptibility of LDL to oxidative modification in moderately hyperlipidemic subjects. Am. J. Clin. Nutr. 2003, 77, 783-795. [CrossRef]

39. Domenichiello, A.F.; Kitson, A.P.; Bazinet, R.P. Is docosahexaenoic acid synthesis from $\alpha$-linolenic acid sufficient to supply the adult brain? Prog. Lipid Res. 2015, 59, 54-66. [CrossRef]

40. Zhang, T.; Zhao, S.; Li, W.; Ma, L.; Ding, M.; Li, R.; Liu, Y. High-fat diet from perilla oil induces insulin resistance despite lower serum lipids and increases hepatic fatty acid oxidation in rats. Lipids Health Dis. 2014, 13, 15. [CrossRef]

41. Kumar, N.; Gupta, G.; Anilkumar, K.; Fatima, N.; Karnati, R.; Reddy, G.V.; Giri, P.V.; Reddanna, P. 15-Lipoxygenase metabolites of $\alpha$-linolenic acid, [13-(S)-HPOTrE and 13-(S)-HOTrE], mediate anti-inflammatory effects by inactivating NLRP3 inflammasome. Sci. Rep. 2016, 6, 31649. [CrossRef] [PubMed]

42. Fukumitsu, S.; Villareal, M.O.; Onaga, S.; Aida, K.; Han, J.; Isoda, H. alpha-Linolenic acid suppresses cholesterol and triacylglycerol biosynthesis pathway by suppressing SREBP-2, SREBP-1a and -1c expression. Cytotechnology 2013, 65, 899-907. [CrossRef] [PubMed]

43. Gregory, M.K.; Gibson, R.A.; Cook-Johnson, R.J.; Cleland, L.G.; James, M.J. Elongase reactions as control points in long-chain polyunsaturated fatty acid synthesis. PLoS ONE 2011, 6, e29662. [CrossRef] [PubMed]

44. Rosell, M.S.; Lloyd-Wright, Z.; Appleby, P.N.; Sanders, T.A.B.; Allen, N.E.; Key, T.J. Long-chain n-3 polyunsaturated fatty acids in plasma in British meat-eating, vegetarian, and vegan men. Am. J. Clin. Nutr. 2005, 82, 327-334. [CrossRef]

45. Mann, N.; Pirotta, Y.; O'Connell, S.; Li, D.; Kelly, F.; Sinclair, A. Fatty acid composition of habitual omnivore and vegetarian diets. Lipids 2006, 41, 637-646. [CrossRef]

46. Welch, A.A.; Shakya-Shrestha, S.; Lentjes, M.A.H.; Wareham, N.J.; Khaw, K.T. Dietary intake and status of n-3 polyunsaturated fatty acids in a population of fish-eating and non-fish-eating meat-eaters, vegetarians, and vegans and the product-precursor ratio [corrected] of alpha-linolenic acid to long-chain n-3 polyunsaturated fatty acids: Results from the EPIC-Norfolk cohort. Am. J. Clin. Nutr. 2010, 92, 1040-1051. [CrossRef] [PubMed]

47. Cho, H.P.; Nakamura, M.T.; Clarke, S.D. Cloning, expression, and nutritional regulation of the mammalian $\Delta-6$ desaturase. J. Biol. Chem. 1999, 274, 471-477. [CrossRef]

48. Leonard, A.E.; Kelder, B.; Bobik, E.G.; Chuang, L.T.; Lewis, C.J.; Kopchick, J.J.; Mukerji, P.; Huang, Y.S. Identification and expression of mammalian long-chain PUFA elongation enzymes. Lipids 2002, 37, 733-740. [CrossRef]

49. Igarashi, M.; DeMar, J.C.J.; Ma, K.; Chang, L.; Bell, J.M.; Rapoport, S.I. Docosahexaenoic acid synthesis from alpha-linolenic acid by rat brain is unaffected by dietary n-3 PUFA deprivation. J. Lipid Res. 2007, 48, 1150-1158. [CrossRef]

50. Moore, S.A.; Yoder, E.; Murphy, S.; Dutton, G.R.; Spector, A.A. Astrocytes, not neurons, produce docosahexaenoic acid (22:6 omega-3) and arachidonic acid (20:4 omega-6). J. Neurochem. 1991, 56, 518-524. [CrossRef]

51. Igarashi, M.; Ma, K.; Chang, L.; Bell, J.M.; Rapoport, S.I. Dietary n-3 PUFA deprivation for 15 weeks upregulates elongase and desaturase expression in rat liver but not brain. J. Lipid. Res. 2007, 48, 2463-2470. [CrossRef] [PubMed]

52. Kirsch, I.; Deacon, B.J.; Huedo-Medina, T.B.; Scoboria, A.; Moore, T.J.; Johnson, B.T. Initial severity and antidepressant benefits: A meta-analysis of data submitted to the Food and Drug Administration. PLoS Med. 2008, 5, e45. [CrossRef] [PubMed]

53. Marazziti, D. Understanding the role of serotonin in psychiatric diseases. F1000Research 2017, 6, 180. [CrossRef] 
54. Khan, A.; Leventhal, R.M.; Khan, S.R.; Brown, W.A. Severity of depression and response to antidepressants and placebo: An analysis of the Food and Drug Administration database. J. Clin. Psychopharmacol. 2002, 22, 40-45. [CrossRef] [PubMed]

55. Levant, B.; Ozias, M.K.; Davis, P.F.; Winter, M.; Russell, K.L.; Carlson, S.E.; Reed, G.A.; McCarson, K.E. Decreased brain docosahexaenoic acid content produces neurobiological effects associated with depression: Interactions with reproductive status in female rats. Psychoneuroendocrinology 2008, 33, 1279-1292. [CrossRef] [PubMed]

56. Papakostas, G.I.; Fan, H.; Tedeschini, E. Severe and anxious depression: Combining definitions of clini-cal sub-types to identify patients differentiallyresponsive to selective serotonin reuptake inhibitors. Eur. Neuropsychopharmacol. 2011, 22, 347-355. [CrossRef]

57. Vancassel, S.; Leman, S.; Hanonick, L.; Denis, S.; Roger, J.; Nollet, M.; Bodard, S.; Kousignian, I.; Belzung, C.; Chalon, S. n-3 polyunsaturated fatty acid supplementation reverses stress-induced modifications on brain monoamine levels in mice. J. Lipid Res. 2008, 49, 340-348. [CrossRef]

58. Vines, A.; Delattre, A.M.; Lima, M.M.S.; Rodrigues, L.S.; Suchecki, D.; Machado, R.B.; Tufik, S.; Pereira, S.I.R.; Zanata, S.M.; Ferraz, A.C. The role of 5-HT(1)A receptors in fish oil-mediated increased BDNF expression in the rat hippocampus and cortex: A possible antidepressant mechanism. Neuropharmacology 2012, 62, 184-191. [CrossRef]

59. Freeman, M.P.; Hibbeln, J.R.; Wisner, K.L.; Davis, J.M.; Mischoulon, D.; Peet, M.; Keck, P.E.J.; Marangell, L.B.; Richardson, A.J.; Lake, J.; et al. Omega-3 fatty acids: Evidence basis for treatment and future research in psychiatry. J. Clin. Psychiatry 2006, 67, 1954-1967. [CrossRef]

60. Lin, P.Y.; Su, K.P. A meta-analytic review of double-blind, placebo-controlled trials of antidepressant efficacy of omega-3 fatty acids. J. Clin. Psychiatry 2007, 68, 1056-1061. [CrossRef]

61. Delion, S.; Chalon, S.; Guilloteau, D.; Besnard, J.C.; Durand, G. alpha-Linolenic acid dietary deficiency alters age-related changes of dopaminergic and serotoninergic neurotransmission in the rat frontal cortex. J. Neurochem. 1996, 66, 1582-1591. [CrossRef] [PubMed]

62. Takeuchi, T.; Fukumoto, Y.; Harada, E. Influence of a dietary n-3 fatty acid deficiency on the cerebral catecholamine contents, EEG and learning ability in rat. Behav. Brain Res. 2002, 131, 193-203. [CrossRef]

63. Mathieu, G.; Denis, S.; Langelier, B.; Denis, I.; Lavialle, M.; Vancassel, S. DHA enhances the noradrenaline release by SH-SY5Y cells. Neurochem. Int. 2010, 56, 94-100. [PubMed]

64. Bowen, R.A.R.; Clandinin, M.T. Dietary low linolenic acid compared with docosahexaenoic acid alter synaptic plasma membrane phospholipid fatty acid composition and sodium-potassium ATPase kinetics in developing rats. J. Neurochem. 2002, 83, 764-774. [CrossRef]

65. Storey, J.D.; Robertson-Beattie, J.E.; Reid, I.C.; Mitchell, S.N.; Balfour, D.J.K. Behavioural and neurochemical responses evoked by repeated exposure to an elevated open platform. Behav. Brain Res. 2006, 166, 220-229. [CrossRef]

66. Harauma, A.; Moriguchi, T. Dietary n-3 fatty acid deficiency in mice enhances anxiety induced by chronic mild stress. Lipids 2011, 46, 409-416. [CrossRef]

67. DeMar, J.C.J.; Ma, K.; Bell, J.M.; Igarashi, M.; Greenstein, D.; Rapoport, S.I. One generation of n-3 polyunsaturated fatty acid deprivation increases depression and aggression test scores in rats. J. Lipid Res. 2006, 47, 172-180. [CrossRef]

68. Song, C.; Leonard, B.E.; Horrobin, D.F. Dietary ethyl-eicosapentaenoic acid but not soybean oil reverses central interleukin-1-induced changes in behavior, corticosterone and immune response in rats. Stress 2004, 7, 43-54. [CrossRef]

69. Farooqui, A.A.; Horrocks, L.A.; Farooqui, T. Modulation of inflammation in brain: A matter of fat. J. Neurochem. 2007, 101, 577-599. [CrossRef] [PubMed]

70. Bazan, N.G. Neuroprotectin D1 (NPD1): A DHA-derived mediator that protects brain and retina against cell injury-induced oxidative stress. Brain Pathol. 2005, 15, 159-166. [CrossRef]

71. Lee, J.Y.; Plakidas, A.; Lee, W.H.; Heikkinen, A.; Chanmugam, P.; Bray, G.; Hwang, D.H. Differential modulation of Toll-like receptors by fatty acids: Preferential inhibition by n-3 polyunsaturated fatty acids. J. Lipid Res. 2003, 44, 479-486. [CrossRef] [PubMed]

72. Brites, D.; Fernandes, A. Neuroinflammation and depression: Microglia activation, extracellular microvesicles and microRNA dysregulation. Front. Cell. Neurosci. 2015, 9, 476. [CrossRef] [PubMed] 
73. Miller, L.J.; Girgis, C.; Gupta, R. Depression and related disorders during the female reproductive cycle. Womens Health (Lond.) 2009, 5, 577-587. [CrossRef]

74. Maki, P.M.; Freeman, E.W.; Greendale, G.A.; Henderson, V.W.; Newhouse, P.A.; Schmidt, P.J.; Scott, N.F.; Shively, C.A.; Soares, C.N. Summary of the National Institute on Aging-sponsored conference on depressive symptoms and cognitive complaints in the menopausal transition. Menopause 2010, 17, 815-822. [CrossRef] [PubMed]

75. Ciappolino, V.; Mazzocchi, A.; Enrico, P.; Syrén, M.L.; Delvecchio, G.; Agostoni, C.; Brambilla, P. N-3 Polyunsatured Fatty Acids in Menopausal Transition: A Systematic Review of Depressive and Cognitive Disorders with Accompanying Vasomotor Symptoms. Int. J. Mol. Sci. 2018, 19, 1849. [CrossRef]

(C) 2020 by the authors. Licensee MDPI, Basel, Switzerland. This article is an open access article distributed under the terms and conditions of the Creative Commons Attribution (CC BY) license (http://creativecommons.org/licenses/by/4.0/). 